\title{
SISTEM INFORMASI WISATA PERMANDIAN AIR PANAS LEJJA KAB. SOPPENG SEBAGAI MEDIA INFORMASI PARIWISATA BERBASIS WEB
}

\author{
Alfiya NFH $^{1}$, Edi Suhardi Rahman ${ }^{2}$, Namirah Aprisani ${ }^{3}$ \\ ${ }^{1}$ Program Studi Pendidikan Teknik Informatika dan Komputer \\ Alifya.nfh@unm.ac.id \\ ${ }^{2}$ Program Studi Pendidikan Teknik Elektro \\ edisuhardi@unm.ac.id \\ ${ }^{3}$ Program Studi Pendidikan Teknik Informatika dan Komputer \\ namirah.aprisani98@gmail.com
}

\begin{abstract}
ABSTRAK
Penelitian ini merupakan penelitian pengembangan (Research and Development). Penelitian ini bertujuan untuk membuat Sistem Informasi Wisata Lejja berbasis Web di Kabupaten Soppeng. Penelitian ini menggunakan model pengembangan waterfall dalam tahap membangun waterfall, analisa kebutuhan, desain sistem, penulisan kode program, pengujian dan penerapan program. Teknik analisis data yang digunakan adalah pengujian ISO 25010 menggunakan 8 karakteristik, yakni functionality suitability, portability, usability, reliability, performance effeciency, security, maintability dan, Compatibility Untuk pengujian functionality suitability menggunakan instrumen validasi, untuk pengujian portability menggunakan software browserstack, sedangkan pengujian usability menggunakan kuesioner yang berisi 30 pertanyaan. Untuk reliability menggunakan pengujian software webserver stress tool, pengujian performance effeciency menggunakan GTMetrix, pengujian security menggunakan software malware removal, pengujian maintability dilakukan menggunakan instrumen dan pengujian Compatibility menggunakan software sortsite. Hasil pengujian dari functionality suitability menunjukkan tingkat kelayakan $100 \%$, untuk hasil pengujian reliability sistem dinyatakan layak karena sistem dapat berjalan dengan baik dengan tingkat keberhasilan rata-rata 99,61\%. Pada pengujian portability menunjukkan sistem dapat berjalan dengan baik. untuk pengujian usability menunjukkan tingkat kelayakan 90,9\%. Pengujian performance efficiency menunjukkan nilai baik. Untuk Pengujian Security menunjukkan nilai Baik, Pengujian Maintability menunjukkan nilai baik, dan pengujian Compatibility menunjukkan sistem berjalan dengan baik.
\end{abstract}

Kata Kunci: Sistem Informasi, Pengembangan, Parawisata

\section{LEJJA HOT WATER TOURISM INFORMATION SYSTEM KAB. SOPPENG AS A WEB- BASED TOURISM INFORMATION MEDIA}

\begin{abstract}
This research is a research and development (Research and Development). This study aims to create a Web-based Lejja Tourism Information System in Soppeng Regency. This study uses the waterfall development model in the waterfall building stage, needs analysis, system design, writing program code, testing and implementing the program. The data analysis technique used is ISO 25010 testing using 8 characteristics, namely functionality suitability, portability, usability, reliability, performance efficiency, security, maintability and, Compatibility. For testing functionality suitability using validation instruments, for portability testing using browserstack software, while usability testing using a questionnaire containing 30 questions. For reliability using the webserver stress tool software testing, performance efficiency testing using GTMetrix, security testing using malware removal software, maintability testing using instruments and Compatibility testing using sortsite software. The test results from the functionality suitability show the feasibility level of $100 \%$, for the results of the system reliability testing it is declared feasible because the system can run well with an average success rate of $99.61 \%$. The portability test shows the system can run well. for usability testing shows a feasibility level of $90.9 \%$. Performance efficiency test shows a good value. The Security Test shows a Good value, the Maintability Test shows a good value, and the Compatibility test shows the system is running well.
\end{abstract}

Keyword: Information Systems, Development, Tourism 


\section{PENDAHULUAN}

Perkembangan teknologi berbasis internet pada saat ini sudah semakin maju, dimana melalui jaringan internet ini terdapat informasi dan pengetahuan yang berguna untuk banyak orang. Kemajuan teknologi informasi dan komunikasi sangat pesat dan merambah banyak aspek kehidupan manusia terutama bagaimana pemanfaaatan media internet dalam meningkatkan mutu dan kualitas kerja suatu instansi sebagai kekuatan untuk menghadapi persaingan yang semakin ketat dewasa ini[1]. Pengolahan sektor rill secara efektif dan potensial adalah syarat mutlak untuk mencapai tujuan pembangunan yang berkesinambungan yang secara merata dan ramah lingkungan. Termasuk di Kantor Dinas Kebudayaan dan Pariwisata di Kabupaten Soppeng sebagai instansi pemerintah yang meningkatkan efektifitas dan efisien kerja lembaga ini.

Salah satunya adalah Permandian Air Panas Lejja merupakan salah satu objek wisata unggulan yang banyak dikunjungi oleh wisatawan mancanegara [2]. Permandian air panas lejja ini sangat berpotensi sebagai salah satu objek wisata yang sangat berpengaruh bagi perekonomian masyarakat dan pemerintahan, akan tetapi objek wisata itu masih terabaikan dan, belum terjamah, bahkan belum banyak masyarakat yang tahu, penyampaian informasinya masih manual seperti pemberian brosur, dilakukan jika ada wisatawan yang datang berkunjung ke suatu objek wisata yang dikunjunginya. Informasi yang dibuat oleh Dinas Pariwista setempat menjadi sangat terbatas karena masyarakat luas tidak bisa mendapatkan informasi tentang kepariwisataan. Kendala ini berakibat kepada kurangnya promosi, dan sistem pemesanan serta pengelolaan yang belum tertata dengan baik. Pemesanan paket wisata oleh wisatawan hanya dapat dilakukan dengan menghubungi pihak pengelola melalui telepon maupun pesan singkat dengan menyebutkan data diri, tanggal kunjungan, dan jumlah rombongan, tetapi calon pengunjung tidak diberi kepastian akan ketersediaan daya tampung secara langsung [3]. Selain itu informasi yang diberikan lewat media booklet atau brosur kurang menarik. Media alternatif ini perlu dibuat untuk menginformasikan pariwista Kabupaten Soppeng agar bisa dinikmati masyarakat luas yaitu dengan melalui fasilitas internet. Untuk mengatasi hal tersebut diperlukan adanya suatu sistem informasi yang cepat, tepat dan akurat, agar setiap objek wisata yang dikenal luas oleh masyarakat sekitar pada khususnya da wisatawan pada umumnya.

\section{METODE PENELITIAN}

\section{A. Jenis Penelitian}

Jenis penelitian yang digunakan yaitu metode penelitian dan pengembangan (Reseacrh and Development). Model perancangan dimulai dari analisis kebutuhan, lalu desain, pengkodean, pengujian, dan terakhir pemeliharaan[4]. Penelitian ini merancang sebuah Sistem Informasi Pariwisata Berbasis Web. Dengan adanya sistem tersebut, akan dijadikan sebagai bahan promosi objek wisata Permandian air panas Lejja di Kabupaten Soppeng.

\section{B. Model Pengembangan}

Model pengembangan yang digunakan dalam penelitian ini adalah model Watefall. Model waterfall digunakan membangun perangkat lunak secara sekuensial melalui tahapan yang harus dijalankan untuk keberhasilan membangun sebuah perangkat lunak [5]. Model Waterfall adalah pengerjaan dari suatu sistem yang dilakukan secara berurutan atau secara linear. Secara garis besar model waterfall mempunyai langkah-langkah sebagai berikut: Analisa, Desain, Penulisan, Pengujian, Penerapan serta Pemeliharaan [6].

\section{Porsedur Perancangan}

Perancangan ini mencakup diagram konteks, DFD, ERD, flowchart, use case diagram, activity diagram, dan interface [7], yang menghasilkan sistem lebih baik. Proses yang dirancang diuraikan menjadi beberapa bagian yang dapat membentuk sistem tersebut menjadi satu kesatuan komponen.

\section{Diagram Konteks}

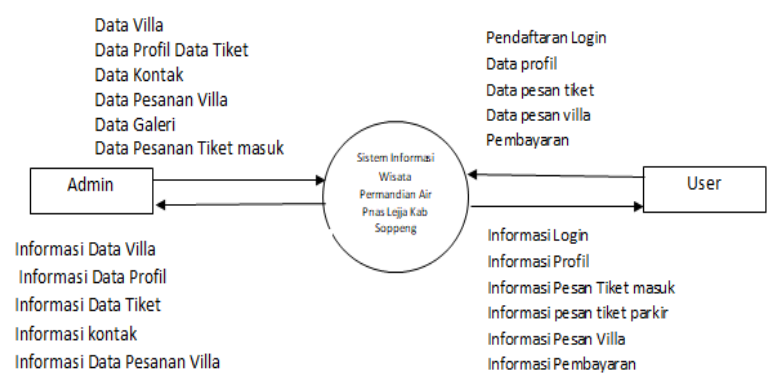

Gambar 1. Diagram Konteks

Model diagram konteks pada Gambar 1 Diagram Konteks dapat diartikan bahwa: Administrator, dapat melakukan pengolahan data seperti melakukan Mengelola data login, mengelola pesanan, serta mengelola data informasi wisata sedangkan user (pengunjung), dapat menginput data pemesanan tiket dan pembookingan villa diform pemesanan serta melihat informasi wisata. 


\section{Data Flow Diagram}

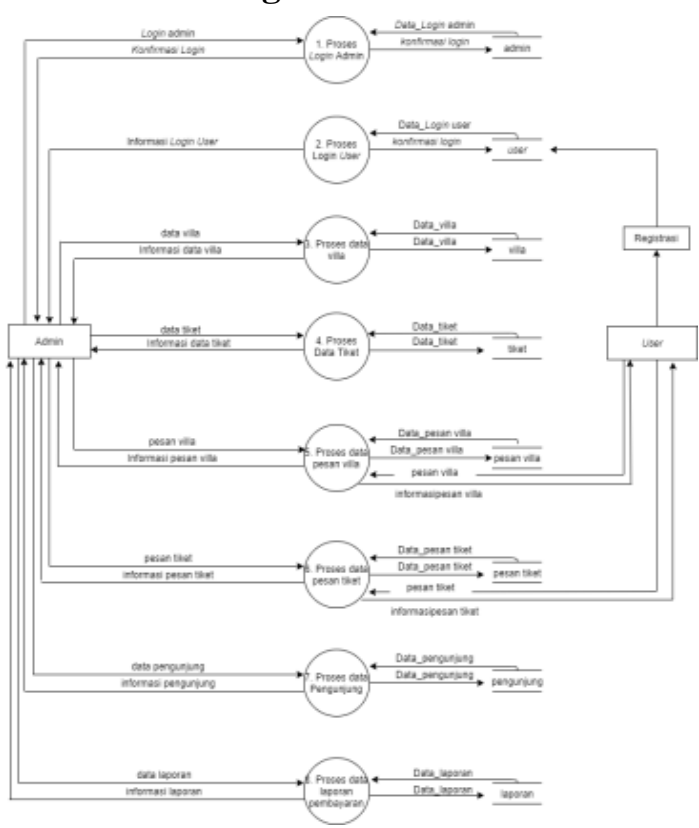

Gambar 2. Data Flow Diagram

Diagram aliran data merupakan model dari sistem untuk menggambarkan pembagian sistem ke modul yang lebih kecil [8]. Fungsi dari Data Flow Diagram (DFD) adalah untuk lebih memperjelas gambaran mengenai sistem tersebut terutama aliran data dalam sistem tersebut.

\section{Flowchart}

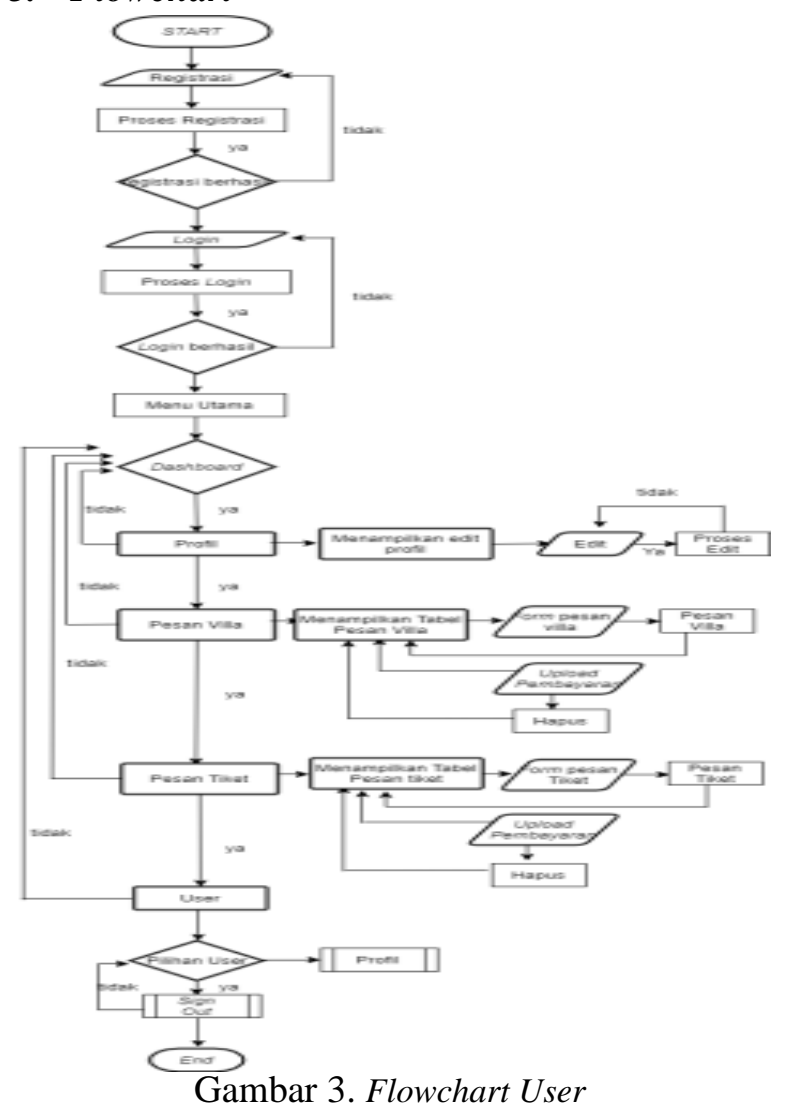

Diagram alir pemakai (user) menggambarkan proses dalam sistem yang dilakukan para pemakai ketika mereka memanfaatkan atau mencari infomasi yang diinginkan oleh user.

\section{Flowchart Admin}

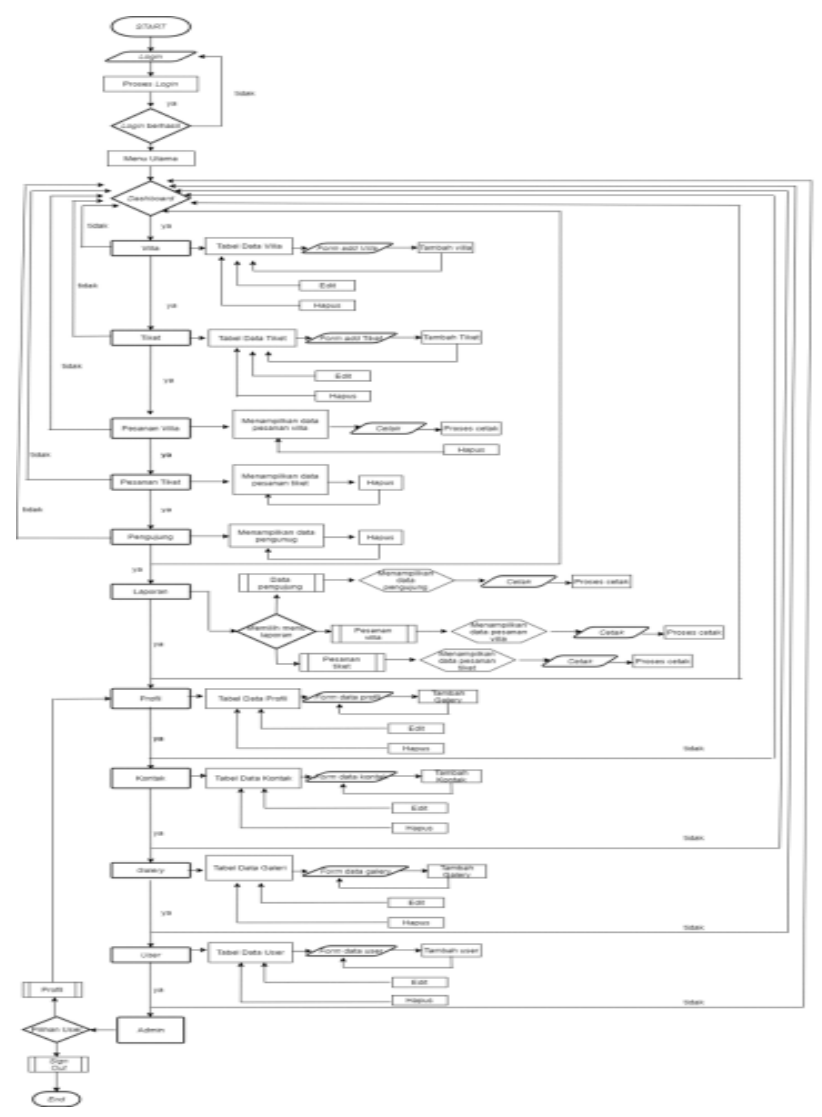

Gambar 4. flowchart admin

Diagram alir admin adalah merupakan proses yang dilakukan oleh seorang administrator dalam melakukan perubahan atau perbaikan dalam sistem informasi yang disampaikan berdasarkan informasi terbaru

\section{Teknik Analisis Data}

Pada penelitian sistem informasi wisata berbasis web ini hanya menggunakan 8 karakter kualitas berdasarkan standar pengujian perangkat lunak ISO 25010 .

\section{Analisis Functionality Suibility}

Pengujian ditentukan dari hasil skor pengujian persentase untuk masing-masing instrument dengan menggunakan dalam bentuk checklist dan dengan pilihan jawaban ya-tidak. Jawaban responden dengan skor (ya) bernilai 1 dan skor (tidak) bernilai 0 .

Hasil skor tersebut kemudian dihitung dengan matriks Feature Completeness untuk mengukur sejauh mana fitur-fitur yang ada di desain dapat benarbenar di implementasikan. Berikut adalah rumus perhitungan Feature Completeness [9]. 


$$
\mathrm{X}=\mathrm{I} / \mathrm{P}
$$

Keterangan :

I = Jumlah fitur yang berhasil di implementasikan

$\mathrm{P}=$ Jumlah fitur yang dirancang

\section{Analisis Portability}

Pengujian aspek portability dilakukan dengan menjalankan sistem di beberapa web browser yang ditentukan oleh peneliti, yaitu Google Chrome, Mozilla Firefox, Internet Explorer, Opera, dan UC Browser. Sistem dinyatakan lolos uji aspek portability apabila sistem dapat berjalan dengan baik di beberapa web browser tersebut tanpa ada eror.

\section{Analisis Usability}

Pengujian pada aspek usability menggunakan skala likert dengan gradasi jawaban dari sangat positif hingga sangat negatif. Jawaban tersebut diperoleh dari pendapat dan presepsi pengguna terhadap aplikasi yang dikembangkan. Dalam menganalisis usability secara kauntitatif maka digunakan skala pengukuran Likert [10], seperti pada Tabel 1 berikut:

\begin{tabular}{ccc}
\multicolumn{2}{c}{ TABEL 1. KLASIFIKASI SKOR SKALA LIKERT } \\
\hline No & Kategori & Skor \\
\hline 1 & Sangat setuju & 5 \\
2 & Setuju & 4 \\
3 & Kurang Setuju & 3 \\
4 & Tidak setuju & 2 \\
5 & Sangat tidak setuju & 1 \\
\hline
\end{tabular}

Skor tersebut dihitung menggunakan rumus konversi ke persentase skor untuk mencari kriteria interprestasi skor hasil pengujian usability. Skor yang diperoleh dari responden kemudian dicari untuk mendapatakan kriteria interprestasi hasil pengujian usability dengan rumus persentase kelayakan menurut[11]:

$$
\% \text { Skor }=\frac{\text { skor total }}{\text { skor maksimal }} \times 100 \%
$$

Setelah mendapatkan persentase jawaban, responden selanjutnya diberikan penafsiran atau penalaian terhadap hasil penelitian. Peneliti menggunakan metode penafsiran yang dikemukakan oleh [12] seperti Tabel 2.

TABEL 2. KONVERSI KUANTITATIF DAN PERSENTASE KELAYAKAN

\begin{tabular}{cll}
\multicolumn{3}{c}{ PERSENTASE KELAYAKAN } \\
\hline No & Persentase Skor & Kategori \\
\hline 1 & $81-100$ & Sangat layak \\
2 & $61-80$ & Layak \\
3 & $41-60$ & Cukup layak \\
4 & $21-40$ & Tidak layak \\
5 & $<21$ & Sangat Tidak \\
& & Layak \\
\hline
\end{tabular}

\section{Analisis Reliablity}

Pengujian pada aspek reliability menggunakan metode pengujian yaitu stress testing. Stress testing digunakan untuk menguji stabilitas dan keandalan sistem. Tes ini dapat menentukan sistem pada ketahanan dan penanganan kesalahan dalam kondisi beban yang sangat berat. Analisis pada aspek reliability menggunakan software WAPT (web application performance testing) yaitu sebuah tool software yang digunakan untuk menghitung jumlah success dan fail pada 3 aspek yaitu succesful dan failed sessions, pages, dan hits. Pada pengujian stress testing, aplikasi dijalankan pada periode waktu tertentu dan diakses secara bersamaan oleh pengguna [13]. Hasil yang diperoleh kemudian dibandingkan dengan standar Telcordia, dengan nilai reabilitas adalah sekitar 0,95 atau 95\% [14].

\section{Analisa Perfomence Effeciency}

Pengujian ini dilakukan dengan menghitung ratarata skor semua halaman dan waktu respon yang diuji menggunakan GTmetrix [15]. GTMetrix digunakan karena kelebihan GTMetrix adalah analisisnya yang stabil dengan tingkat konsistensi pengukuran yang sahih. Standar yang dapat digunakan menurut [16].

\section{Analisa Compatibility}

Pengujian Compatibility ini merupakan testing yang dilakukan dengan menjalankan produk, sistem atau komponen dengan perangkat keras dan/ atau perangkat lunak dalam suatu sumber daya yang sama.

\section{E. Teknik Pengumpulan Data}

Pengumpuan data yang dilakukan yaiut degan dengan menggunakan ISO. ISO 25010 merupakan standar pengujian international dalam penentuan kualitas perangkat lunak [17]. Pengujian kualitas perangkat lunak ISO/IEC 20510 dengan mengimplementasikan aspek pengujian perangkat lunak yakni functional suitability, performance efficiency, dan usability [18].

\section{F. Instrumen Penelitian}

Analisis data yang digunakan dalam penelitian ini adalah analisis deskriptif kauntitatif. Data yang dianalisis barasal dari data persepsi dosen dan penilaian ahli yang diperoleh dari analisis angket. Data yang didapatkan dari setiap instrumen akan dihitung rata-rata menggunakan rumus [19].

$$
\bar{x}=\frac{\sum x}{n}
$$

Dimana :

$\bar{x}=$ skor rata-rata

$x=$ skor total item

$n$ = jumlah item

Sedangkan untuk menghitung skor persentase kelayakan menggunakan rumus [20], 
Kelayakan $(\%)=\frac{\text { Skor yang diobservasi }}{\text { Skor yang diharapkan }} \times 100 \%$

Setelah data hasil berupa nilai deskriptif kuantitatif, nilai yang diperoleh dikonversi menjadi nilai kualitatif berskala 5 dengan skala Likert. Konversi persentase ke pernyataan seperti dalam Tabel 3 [21].

\begin{tabular}{cll}
\multicolumn{2}{c}{ TABLE 3. PENYESUAIAN INTERPRETASI LIKERT } \\
\hline No & Persentase & Interpretasi \\
\hline 1 & $0-20$ & Sangat Tidak Layak \\
2 & $21-40$ & Tidak Layak \\
3 & $41-60$ & Cukup Layak \\
4 & $61-80$ & Layak \\
5 & $81-100$ & Sangat Layak \\
\hline
\end{tabular}

\section{HASIL DAN PEMBAHASAN}

\section{A. HASIL PENELITIAN}

Berdasarkan hasil penelitian yang telah dilakukan maka diperoleh sebuah sistem, yaitu Sistem Informasi Wisata Permandian Air Panas Lejja Kab. Soppeng Sebagai Media Informasi Pariwisata Berbasis Web. Sistem ini untuk memudahkan masyarakat ataupun calon wisatawan yang akan berkunjung ke Permandian Air Panas Lejja.

\section{Antar Muka Sistem}

Sistem ini memiliki tampilan yang menarik dan mudah dipahami, dan adanya aspek user friendly sehingga memudahkan pengguna atau calon pengunjung dalam memesan tiket, villa atau mencari informasi tentang wisata Permandian Air Panas Lejja. Sistem ini dikelola oleh halaman administrator, yang memiliki akses penuh terhadap semua data yang ada disistem.

\section{Analisis Kebutuhan}

Tujuan dari analisis kebutuhan ini agar dalam proses perancangan sistem dapat tepat sasaran dan difungsikan dengan baik di TWA Lejja . Berdasarkan hasil wawancara dengan Staff Perusda Lejja Kabupaten Soppeng. Perlu dibuatkan sistem informasi wisata yang bertujuan dapat memudahkan staff wisata untuk mengelola data wisata dan agar memudahkan calon wisatawan untuk melakukan pemesanan tiket wisata ataupun pembookingan villa secara online.

\section{Implementasi Sistem}

Setelah sistem dikatakan layak pada uji validasi dilanjutkan dengan Implementasi Sistem. Sistem ini di implementasikan dengan melakukan demonstrasi sistem.

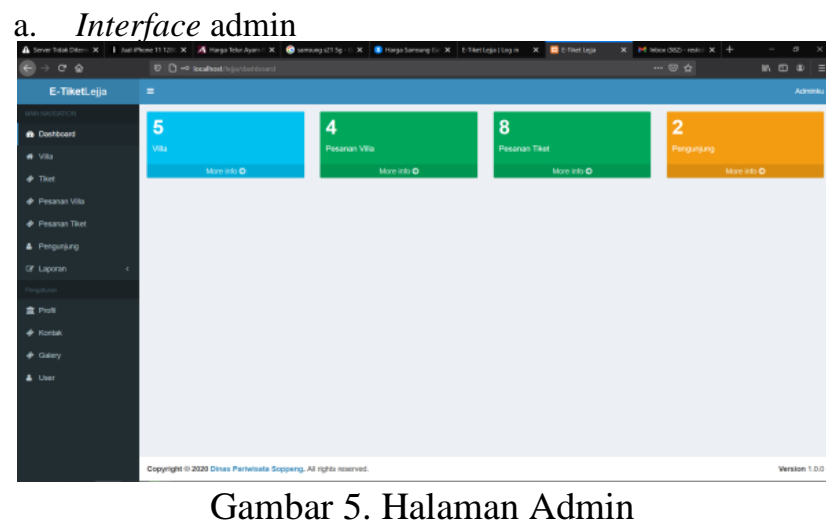

Merupakan tampilan utama admin, dalam tampilan ini admin dapat melakukan semua aktifitas dalam mengelola sistem. Mulai dari mengedit, menghapus, dan menambahkan.

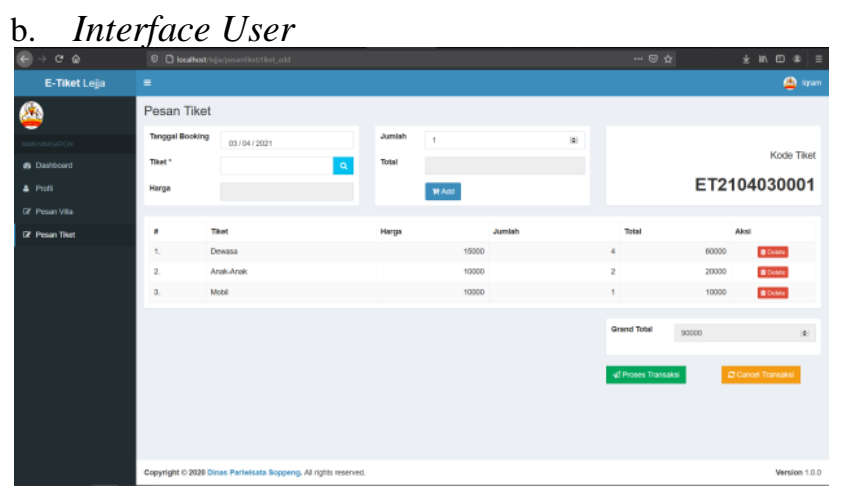

Gambar 6. Halaman Pemesanan Tiket

Halaman pemesanan tiket, dimana user atau pengujung melakukan proses pemesanan tiket masuk wisata, pada pemesanan tiket terdapat harga tiket masuk anak-anak dewasa dan tiket masuk mobil dan motor

\section{Hasil Pengujian ISO 25010}

a. Aspek funcionality suitability

\begin{tabular}{llll}
\multicolumn{4}{c}{ TABEL 4. REKAPOTULASI PENGUJIAN AHLI SISTEM } \\
\hline Validator & $\begin{array}{l}\text { Jumlah } \\
\text { soal yang } \\
\text { di uji (P) }\end{array}$ & $\begin{array}{l}\text { Jumlah fitur } \\
\text { yang berhasil di } \\
\text { uji (I) }\end{array}$ & $\begin{array}{l}\text { Feature } \\
\text { Completenes }\end{array}$ \\
\hline 1 & 38 & 38 & 1 \\
2 & 38 & 38 & 1 \\
\hline
\end{tabular}

b. Aspek Portability

TABEL 5. UJI KELAYAKAN

\begin{tabular}{cllcc}
\hline No & Perangkat & \multicolumn{1}{c}{ Browser } & Berhasil & Gagal \\
\hline 1 & Windows 8 & Microsoft Edge & 1 & 0 \\
2 & Windows 8 & Internet Explorer & 1 & 0 \\
3 & Windows 8 & Opera & 1 & 0 \\
4 & Windows & Mozilla Firefox & 1 & 0 \\
& 10 & & 1 & 0 \\
5 & $\begin{array}{l}\text { Windows } \\
\text { 10 }\end{array}$ & Google Chrome & & \\
6 & $\begin{array}{l}\text { Oppo reno 3 } \\
\text { pro }\end{array}$ & Google Chrome & 1 & 0 \\
\hline
\end{tabular}




\begin{tabular}{|c|c|c|c|c|}
\hline No & Perangkat & Browser & Berhasi & Gagal \\
\hline 7 & $\begin{array}{l}\text { Samsung } \\
\text { A51 }\end{array}$ & Google Chrome & 1 & 0 \\
\hline 8 & $\begin{array}{l}\text { Samsung } \\
\text { Galaxy Tab } \\
\text { s7 Pro }\end{array}$ & Google Chrome & 1 & 0 \\
\hline 9 & $\begin{array}{l}\text { Iphone } 12 \\
\text { Pro }\end{array}$ & Safari & 1 & 0 \\
\hline 10 & Ipad Pro 9 & Google Chrome & 1 & 0 \\
\hline \multicolumn{3}{|c|}{ Total } & 10 & - \\
\hline \multicolumn{3}{|c|}{$X$} & 1 & - \\
\hline \multicolumn{3}{|c|}{ Kategori } & Baik & - \\
\hline
\end{tabular}

Terlihat pada Tabel 5 kolom berhasil terisi nilai 1 keseluruhan sehingga total nilai dari 10 perangkat yang diujikan memperoleh nilai 10 atau semuanya berhasil. Dari rangkuman ini maka dapat disimpulkan bahwa sistem ini memenuhi aspek portability

c. Aspek Perfomance Effeciency

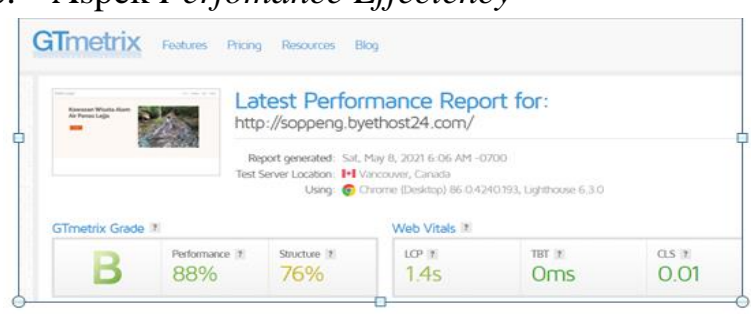

Tabel 6. Hasil Pengujian GT Metrix

Pengujian ini dilakukan dengan menghitung rata-rata skor semua halaman dan waktu respon yang diuji menggunakan GTMetrix. Hasil yang diperoleh kelas GTMetrix memperoleh nilai B dengan perform $88 \%$, struktur $76 \%$ dengan memperoleh nilai 1.4 detik dalam kategori baik

\section{d. Aspek Usability}

Hasil tanggapan pengguna dalam menggunakan sistem ini. Dari rangkuman tersebut diperoleh nilai rata-rata sebesar 90,9\%. Nilai ini dikonversi berdasarkan indikator, Maka nilai ini masuk kedalam kategori sangat layak dan hasil ini menunjukkan bahwa sistem ini memenuhi aspek usability.

TABEL 7. PENGUJIAN USABILITY

\begin{tabular}{lllll}
\hline Responden & Rerata & $\begin{array}{l}\text { Skor } \\
\text { Maks }\end{array}$ & Kategori \\
\hline 30 Orang & 136,8 & 150 & 90,9 & $\begin{array}{l}\text { Sangat } \\
\text { Layak }\end{array}$ \\
\hline
\end{tabular}

Berdasarkan rangkuman tersebut diperoleh nilai rata-rata sebesar 90,9\%. Nilai ini dikonversi berdasarkan indikator. Maka nilai ini masuk kedalam kategori sangat layak dan sistem ini memenuhi aspek usability

\section{e. Aspek Compatibility}

Berdasarkan hasil compatibility testing menunjukkan bahwa tidak ada masalah kritis pada sistem informasi. Pengujian seperti browser IE versi 11, Edge versi 92, Firefox versi 90, safari versi 14, Opera versi 77, chrome versi 92, IOA versi 14 dan Android versi 92 berjalan dengan baik.

\begin{tabular}{|c|c|c|c|c|c|c|c|c|c|c|}
\hline \multirow{2}{*}{$\begin{array}{l}\text { Summary } \\
\text { Errors }\end{array}$} & \multicolumn{3}{|c|}{ Issues } & Pages & \multicolumn{4}{|c|}{ http://kwa-lejja.com/?i=1 } & & \\
\hline & \multicolumn{3}{|c|}{ Accessibility } & \multicolumn{2}{|c|}{ Compatibility } & Search & \multicolumn{2}{|c|}{ Standards } & \multicolumn{2}{|c|}{ Usability } \\
\hline \multicolumn{11}{|c|}{ This tab shows pages that exhibit browser-specific behavior, or trigger browser bug } \\
\hline Bron & & IE & Edge & Firefox & Safari & Opera & Chrome & io & & Android \\
\hline Vers & & 11 & 92 & 90 & 14 & 77 & 92 & $\leq 13$ & 14 & 92 \\
\hline Critical Iss & & () & (-) & () & () & () & () & (-) & () & () \\
\hline Major Iss & & () & () & (9) & ( & ( & () & () & (9) & (9) \\
\hline Minor Iss & & (1) & & (1) & (1) & & & & & \\
\hline
\end{tabular}

\section{Gambar 7. Hasil Pengujian Sortsite}

\section{B. PEMBAHASAN}

Penelitian ini menghasilkan suatu sistem yang bertujuan untuk membantu kinerja pihak Perusahaan Daerah (Perusda) dalam mencapai salah satu tujuannya yaitu memaksimalkan pelayanan terhadap daerah dengan menerapkan sistem informasi wisata berbasis web. Pelayanan yang sebelumnya masih secara manual dan dapat memudahkan masyarakat lokal maupun luar untuk lebih mengenal tentang destinasi wisata alam Lejja. Sistem pelayanan yang dikembangkan awalnya diimplementasikan secara lokal, namun pengembangan lebih lanjut akan dipublikasikan secara online masyarakat lokal hingga mancanegara dapat memperoleh informasi mengenai wisata permandian air panas lejja. Sistem informasi wisata ini dirancang menggunakan bahasa pemrograman PHP (PHP:Personal Home Page Hyeperetext Preprocessor), Javascript. Sehingga setiap halaman pada sistem memiliki desain yang responsif dan mudah digunakan. Berdasarkan hasil pengujian validasi oleh dua ahli, maka sistem ini dinyatakan layak untuk digunakan dengan sedikit revisi. Pengujian selanjutnya yaitu pengujian sistem dengan menggunakan standar ISO 25010 [6] sebagai acuan pengujian. Pengujian dengan standar ISO 25010 pada penelitian ini menggunakan 8 aspek, yaitu functionality suability, Reliability , Portability, Usability, Perfomance Effeciency, Security, Maintability dan Compatibility .

Pengujian Funcionality suability terdiri dari 38 pertanyaan terkait setiap fungsi yang dikembangkan kedalam sistem setiap fungsi dinilai oleh 2 (dua) orang ahli sistem. Yaitu Bapak Udin sidik sidin S.Pd.,M.T dan bapak Hasrul Bakri S.Pd.,M.T. Jawaban dari setiap item pertanyaan menggunakan skala guttman. Setiap fungsi berjalan dengan baik maka ahli akan checklist pada kolom 'Ya'. Apabila fungsi diuji tidak berjalan maka ahli akan memberikan checklist pada kolom 'tidak'. Hasil pengujian dari aspek functionality suitability. Berdasarkan rumus 
diatas $\mathrm{I}=38$ dan $\mathrm{P}=38$ maka feature completeness bernilai 1. Hal ini berarti bahwa aspek functionality suitability sistem informasi yang dikembangkan berada pada kategori baik.

Pengujian Portability berdasarkan hasil pengujian beberapa perangkat dan browser untuk menjalankan sistem ini. Pada tabel terdapat indikator berhasil dan gagal kemudian pada kolom tersebut berisi nilai 0 dan 1 . Nilai 1 menunjukkan nilai "ya" dan nilai 0 menunjukkan nilai "tidak" telihat pada tabel kolom. Berhasil terisi nilai 1 keseluruhan sehingga total nilai dari 10 perangkat yang diujikan memperoleh nilai 10 atau semuanya berhasil. Maka dapat disimpulkan bahwa sistem ini memenuhi aspek portability.

Pengujian Usability pada sistem ini menggunakan kuesioner yang dikembangkan oleh James $\mathrm{R}$ Lewis yang berisi 30 pertanyaan mengenai komputer software. Kuesioner ini dibagikan kepada 45 responden diantaranya 15 responden untuk pegawai Kantor Perusahaan Daerah Kabupaten Soppeng dan 30 responden untuk masyarakat luar. Sehingga mendapatkan tingkat kelayakan $91 \%$ yang diperoleh dari hasil penilaian angket staff wisata dan tingkat kelayakan 90,9 \% untuk analisis tanggapan pengguna.

Pengujian Perfomance Effeciency pengujian ini dilakukan dengan menghitung rata-rata skor semua halaman dan waktu respon yang diuji menggunakan GTMetrix. Hasil yang diperoleh kelas GTMetrix memperoleh nilai B dengan perfoma $88 \%$ struktur $76 \%$ dengan memperoleh nilai 1,4 dtk, aspek mempengaruhi kecepatan sistem dalam peengujian GTMetrix yaitu folder sistem, css, javascript. Nilai ini menunjukkan performance efficiency sistem ini memperoleh nilai yang baik.

Pengujian Compatibility ini dilakukan dengan menggunakan bantuan aplikasi SortSite versi 5.29.818.0. Hasil compatibility testing menunjukkan bahwa tidak ada masalah kritis pada sistem informasi.

Berdasarkan hasil dari penelitian Sistem Informasi Wisata Lejja ini setelah divalidasi dan dilakukan pengujian dengan menggunakan standar ISO 25010 ditinjau dari segi functionality suability, Usability, Perfomance Effeciency, dan Compatibility dapat disimpulkan bahwa sistem informasi ini dapat digunakan oleh pengguna akhir.

\section{SIMPULAN}

1. Berdasarkan hasil penelitian dan pembahasan tentang rancangan sistem informasi pariwisata sebagai media informasi wisata berbasis web di Taman Wisata Permandian Air Panas Lejja Kabupaten Soppeng dapat disimpulkan bahwa sistem informasi tersebut dirancang dengan menggunakan bahasa pemrograman $P H P$ (Hypertext Prepocessor ), database MySQL, HTML (Hyper text Markup Languange), CSS (Cascoding Style Sheet), JavaScript, merupakan sebuah sistem yang dapat digunakan untuk melakukan pelaksanaan penginformasian kepada masyarakat umum ataupun calon wisatawan.

2. Tanggapan pengguna terhadap sistem informasi yang dibuat berbasis web di wisata permandian air panas Lejja menghasilkan interprestasi sangat baik menunjukkan bahwa pengguna dapat menerima perancangan sistem informasi wisata permandian air panas Lejja berbasis web.

\section{DAFTAR PUSTAKA}

[1] U. Rumefi, "Pengaruh Pertumbuhan Ekonomi, Pendapatan Asli Daerah, Dan Dana Alokasi Umum Terhadap Pengalokasian Anggaran Belanja Modal," MAGISTRA: Jurnal Ilmu Manajemen, vol. 2, no. 2, pp. 122-130, 2018.

[2] I. Ummah, "Survei Dayatarik Pengunjung terhadap Fasilitas dan Pelayanan pada Tempat Wisata Permandian Air Panas Lejja Kecamatan Marioriawa Kabupaten Soppeng," UNIVERSITAS NEGERI MAKASSAR, 2019.

[3] M. H. Umar, S. Sudarmi, and R. Riskasari, "Pengembangan Objek Wisata Alam Lejja Dalam Meningkatkan Pendapatan Retribusi Wisata Di Dinas Pariwisata, Kepemudaan Dan Olahraga Kabupaten Soppeng," Kajian Ilmiah Mahasiswa Administrasi Publik (KIMAP), vol. 2, no. 1, pp. 62-76, 2021.

[4] I. Suparyogo, Metode Penelitian Kuantitatif Kualitatif dan $R \& D$. Bandung: Alfabeta. Yogyakarta: Andi, 2001.

[5] D. Vitalocca, E. S. Rahman, and N. M. Abdal, "Pengembangan Aplikasi Kemahasiswaan Jurusan Pendidikan Teknik Elektro (Asik-Jpte) Berbasis Cloud Computing," Jurnal Media Elektrik, vol. 18, no. 1, pp. 1-7, 2021.

[6] M. Mulyadi, Pengelolaan Arsip Berbasis Otomasi. Rafah Press, 2016.

[7] I. Sidharta and M. Wati, "Perancangan dan implementasi sistem informasi urunan desa (URDES) berdasarkan pada pajak bumi dan bangunan," Jurnal Computech \& Bisnis, vol. 9, no. 2, pp. 95-107, 2015. 
[8] A.-B. B. Ladjamudin, "Analisis dan desain sistem informasi," 2005.

[9] A. Acharya and D. Sinha, "Assessing the quality of m-learning systems using ISO/IEC 25010," International Journal of Advanced Computer Research, vol. 3, no. 3, p. 67, 2013.

[10]E. S. Rahman and D. Vitalocca, "Analisis Usabilitas Menggunakan Use Questionnaire Pada Sistem Informasi Smk Negeri 3 Makassar," Jurnal MEKOM (Media Komunikasi Pendidikan Kejuruan), vol. 5, no. 1, pp. 16-22, 2019.

[11]S. Sugiyono, "Metode penelitian kuantitatif dan kualitatif dan R\&D," Alfabeta Bandung, 2010.

[12]A. S. Abigail, Pengembangan Dan Analisis Sistem Informasi Perpustakaan Sekolah Berbasis Website. Skripsi. Yogyakarta: Universitas Negeri Yogyakarta, 2018.

[13]H. Brawijaya, S. Widodo, and S. Samudi, "Pengujian Sistem Informasi Penjualan dan Persediaan Barang Dengan Web Application Load Stress and Performance Testing (WAPT)," Information System For Educators And Professionals: Journal of Information System, vol. 2, no. 2, pp. 125-134-125-134, 2018.

[14]G. P. Sari, J. Marzal, and M. Mauladi, "Rancang Bangun Sistem Informasi Persuratan dan Disposisi Elektronik Universitas Jambi," JUSS (Jurnal Sains dan Sistem Informasi), vol. 1, no. 1, pp. 20-29, 2018.

[15]A. Suprapto and D. Sasongko, "Studi Empiris Evaluasi Performa Website IAIN Salatiga Menggunakan Automated Software Testing," J-SAKTI (Jurnal Sains Komputer dan Informatika), vol. 5, no. 1, pp. 209-218, 2021.

[16]H. Fryonanda and T. Ahmad, "Analisis Website Perguruan Tinggi Berdasarkan Keinginan Search Engine Menggunakan Automated Software Testing GTmetrix," Kalbiscientia: Jurnal Sains dan Teknologi, vol. 4, no. 2, pp. 179-183, 2017.

[17]R. D. Jayanto, "Evaluasi Kualitas Aplikasi Mobile Kamus Istilah Jaringan Pada Platform Android dengan Standar ISO/IEC 25010," Elinvo (Electronics, Informatics, and Vocational Education), vol. 2, no. 2, pp. 178182, 2017.

[18]A. B. David, Mobile application testing best practices to ensure quality-AMDOCS. 2011.
[19]T. N. Sari, “Analisis kualitas dan pengembangan sistem informasi akademik berbasis web menggunakan standard iso 9126," JIKO (Jurnal Informatika dan Komputer), vol. 1, no. 1, 2016.

[20]T. N. Sari, "Analisis kualitas dan pengembangan sistem informasi akademik berbasis web menggunakan standard iso 9126," JIKO (Jurnal Informatika dan Komputer), vol. 1, no. 1, 2016.

[21]Riduwan and Akdon, Rumus dan Data dalam Analisis Statistika. Bandung: Alfabeta, 2008. 